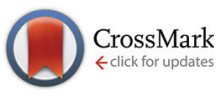

Cite this: Org. Biomol. Chem., 2014, 12,6089

Received 13th June 2014, Accepted 24th June 2014

DOI: $10.1039 / c 4 o b 01228 c$

www.rsc.org/obc

\section{Relative contractile motion of the rings in a switchable palindromic [3]rotaxane in aqueous solution driven by radical-pairing interactions $\uparrow$}

\author{
Leah S. Witus, ${ }^{a}$ Karel J. Hartlieb, ${ }^{a}$ Yuping Wang, ${ }^{a}$ Aleksandrs Prokofjevs, \\ Marco Frasconi, ${ }^{a}$ Jonathan C. Barnes, ${ }^{a, b}$ Edward J. Dale, ${ }^{a}$ \\ Albert C. Fahrenbach ${ }^{a, c, d}$ and J. Fraser Stoddart*a
}

\begin{abstract}
Artificial muscles are an essential component for the development of next-generation prosthetic devices, minimally invasive surgical tools, and robotics. This communication describes the design, synthesis, and characterisation of a mechanically interlocked molecule (MIM), capable of switchable and reversible linear molecular motion in aqueous solution that mimics muscular contraction and extension. Compatibility with aqueous solution was achieved in the doubly bistable palindromic [3]rotaxane design by using radical-based molecular recognition as the driving force to induce switching.
\end{abstract}

The concept of controlling molecular motion at will is an inspiring call to chemists. ${ }^{1}$ The design and synthesis of organic molecules that are capable of achieving movement is the first step towards translating that motion into a macroscopic effect through integration into larger systems. ${ }^{2}$ Some of the most impressive evidence that molecular motion can be translated into macroscopic motion comes from biology, wherein proteins and assemblies of proteins - themselves large molecules and supermolecules - routinely achieve incredible feats, from kinesin pulling organelles along microtubules, to the rotary motion of ATP synthase, to the propulsion that results from bacterial flagellum. ${ }^{3}$ When we turn to the synthetic world, there are still rather few comparable systems. ${ }^{4}$ One class of organic compounds is particularly well suited, however, to containing and exercising moving parts namely, mechanically interlocked molecules ${ }^{5}$ (MIMs). Since MIMs consist of two or more components that cannot be

\footnotetext{
${ }^{a}$ Department of Chemistry, Northwestern University, 2145 Sheridan Road, Evanston, Illinois 60208, USA. E-mail: stoddart@northwestern.edu

${ }^{b}$ Department of Chemistry, Massachusetts Institute of Technology, 77 Massachusetts Avenue, Cambridge, MA 02139, USA

${ }^{c}$ Howard Hughes Medical Institute, Department of Molecular Biology, and Center for Computational and Integrative Biology, Massachusetts General Hospital, Boston, Massachusetts 02114, USA

${ }^{d}$ Earth-Life Science Institute, Tokyo Institute of Technology, 2-12-1 Ookayama, Meguro-ku, Tokyo 152-8551, Japan

$\dagger$ Electronic supplementary information (ESI) available. See DOI: 10.1039/ c4ob01228c
}

separated without breaking a covalent bond, the bond(s) holding the molecule together is (are) called a mechanical bond. In the case of a rotaxane, a dumbbell-shaped component is encircled by a ring, and the inclusion of functional groups on the dumbbell, for which the ring has an affinity, provides recognition sites. When the affinity for one recognition site is increased or decreased relative to another one by a stimulus, this bistability serves as the driving force for the ring moving relative to the dumbbell. A unique interpretation of this design has been reported ${ }^{6}$ previously wherein the dumbbell contains two sets of identical recognition sites, in a constitutionally symmetric, or palindromic, design. Thus, in this prototypical design of a palindromic [3]rotaxane, the two rings achieve a linear contractile motion as they are switched between the inner and outer recognition sites. ${ }^{7}$ This motion (Fig. 1) mimics the molecular motion present in actin and myosin proteins within muscle tissue. ${ }^{3}$ In order to facilitate the next transition of the doubly bistable [3] rotaxane switches - from isolated molecules to integrated systems - and to enable biocompatible applications, these switches must operate in aqueous solution, the major medium of life itself. a)

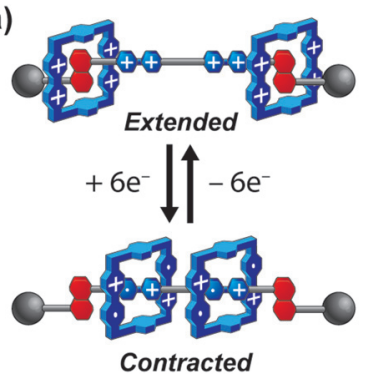

b)

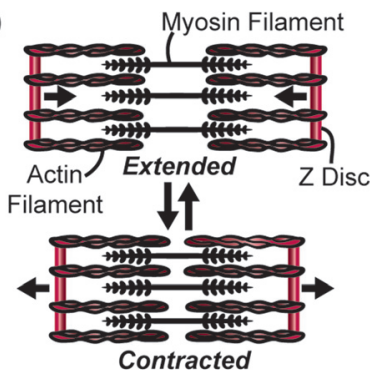

Fig. 1 (a) Graphical representation of the relative motion of the ring components, which undergo a redox-stimulated contraction and expansion in a doubly bistable palindromic [3]rotaxane. (b) The contraction of the sarcomere in biological muscle is achieved through the ATP-driven molecular motion of actin and myosin proteins sliding relative to each other. 


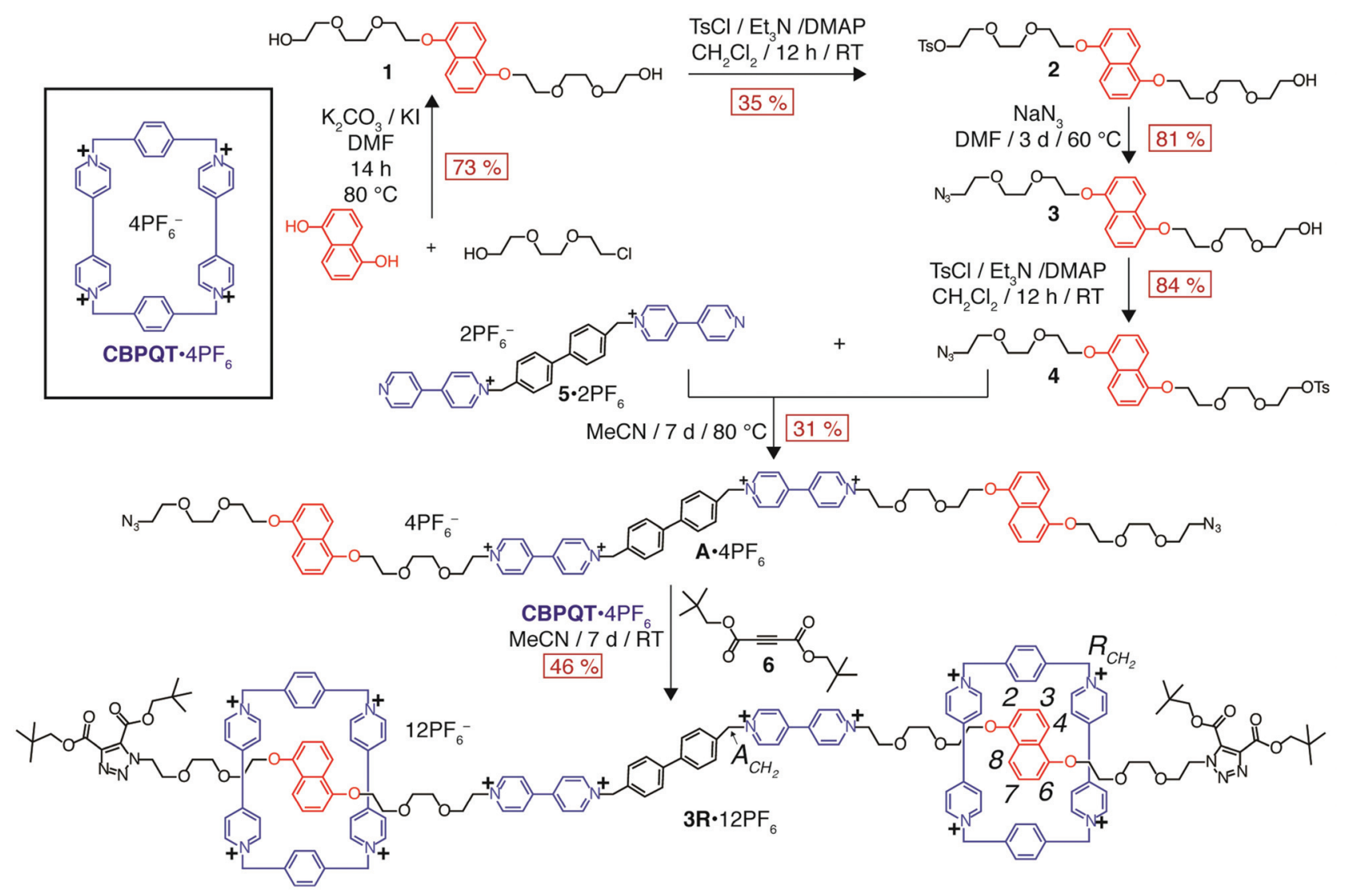

Scheme 1 Synthetic route to the palindromic [3]rotaxane $3 \mathrm{R} \cdot 12 \mathrm{PF}_{6}$ using a threading-followed-by-stoppering approach.

Recently, we have discovered the potential of radical-radical pairing interactions ${ }^{8}$ in the context of MIMs. It has been found that $4,4^{\prime}$-bipyridinium $\left(\mathrm{BIPY}^{2+}\right)$ units, upon reduction to their radical cationic state $\left(\mathrm{BIPY}^{+*}\right)$, form strong inclusion complexes with the reduced diradical, dicationic $\left(\mathbf{C B P Q T}^{2(+\bullet)}\right)$ form of cyclobis(paraquat- $p$-phenylene) $\left(\mathbf{C B P Q T}^{4+}\right)$. The radical-based pairing interaction in the reduced state is strong and represents the driving force for switching to the radical state coconformation $^{8 d}$ (RSCC) in a MIM, a process that is eliminated in the oxidised state by electrostatic repulsions between the positive charges on both components. Thus, redox stimuli initiate rapid and readily reversible switching, but what's more, this radical-based switching mechanism has been shown to occur in aqueous solution. Here, we incorporate this new switching mechanism into a palindromic [3] rotaxane.

The design of a doubly bistable palindromic [3]rotaxane requires two sets of identical recognition sites on the dumbbell. Our design utilises 1,5-dioxynaphthalene (DNP) units as the outer recognition sites, which enter into donor-acceptor interactions with the $\mathbf{C B P Q T}^{4+}$ rings in the oxidised ground state co-conformation (GSCC). After reduction, the diradical, dicationic $\mathbf{C B P Q T}^{2(+\bullet)}$ ring has a strong preference for the inner $\mathrm{BIPY}^{+\bullet}$ recognition sites and a decreased affinity for the DNP units, resulting in a shuttling motion whose reversal is facilitated by the electrostatic repulsion between the positive charges on both the $\mathrm{BIPY}^{2+}$ units and the tetracationic ring upon re-oxidation.

The synthesis of the bistable palindromic [3] rotaxane was performed following the protocol outlined in Scheme 1. In order to achieve higher yields of the desired [3] rotaxane than had previously been possible with clipping-based rotaxanation approaches, ${ }^{6 b}$ we sought to use a threading-followed-by-stoppering protocol for the rotaxane formation. Therefore, the first step was synthesising an axle component, $\mathbf{A} \cdot 4 \mathrm{PF}_{6}$, with azide functionalities at each end to aid and abet the subsequent stoppering reaction. The synthesis of the axle begins with a DNP-tri(ethylene glycol) unit ${ }^{9} \mathbf{1}$ which was subjected to a monotosylation to induce desymmetrisation. ${ }^{10}$ The monotosylate 2 was reacted with sodium azide in order to install an azide group $^{11}$ in $\mathbf{3}$. The remaining hydroxyl group on 3 was then tosylated in order to form $\mathbf{4}$ prior to its reaction with a bisviologen-based core ${ }^{12} \mathbf{5} \cdot 2 \mathrm{PF}_{6}$ to form the axle $\mathbf{A} \cdot 4 \mathrm{PF}_{6}$.

Rotaxanation was achieved by a threading-followed-by-stoppering approach wherein an excess of CBPQT.4PF ${ }_{6}$ was incubated with the axle in $\mathrm{MeCN}$ at room temperature for a week. An electron-deficient alkyne ${ }^{13} \mathbf{6}$ was added to form the stoppers as a result of copper-free Huigsen cycloadditions. ${ }^{14}$ The desired [3] rotaxane $3 \mathbf{R} \cdot 12 \mathrm{PF}_{6}$ was obtained in $46 \%$ yield, along with a small amount $(8 \%)$ of a [2]rotaxane byproduct $\left(2 \mathbf{R} \cdot 8 \mathrm{PF}_{6}\right)$. See synthetic procedures in the ESI. $\dagger$ 
${ }^{1} \mathrm{H}$ NMR spectroscopy of $\mathbf{3 R} \cdot 12 \mathrm{PF}_{6}$ confirmed the hypothesis that, in the non-reduced GSCC, the CBPQT ${ }^{4+}$ rings reside on the DNP recognition units. Fig. 2 shows partial ${ }^{1} \mathrm{H}$ NMR spectra comparing the dumbbell $\mathbf{D} \cdot 4 \mathrm{PF}_{6}$, the [3] rotaxane $3 \mathbf{R} \cdot 12 \mathbf{P F}_{6}$ and the [2] rotaxane $2 \mathbf{R} \cdot 8 \mathbf{P F}_{6}$. An upfield shift was observed for the peaks corresponding to the DNP protons (labelled $\mathrm{H}_{4 / 8}, \mathrm{H}_{2 / 6}$, and $\mathrm{H}_{3 / 7}$ ) in the [2]- and [3]rotaxane, indicating that the DNP units are encircled by $\mathbf{C B P Q T}^{4+}$ rings. This co-conformation was confirmed by through-space interactions observed in the ${ }^{1} \mathrm{H}-{ }^{1} \mathrm{H}$ ROESY NMR spectrum, shown in Fig. S9 in the ESI. $\dagger$ Variable temperature ${ }^{1} \mathrm{H}$ NMR spectra, which were recorded on the [2] rotaxane $\mathbf{2} \mathbf{R} \cdot 8 \mathbf{P F}_{6}$ demonstrate that, in the GSCC, the inner $\mathrm{BIPY}^{2+}$ recognition sites serve as electrostatic barriers preventing the shuttling of the ring from one DNP recognition site to the other. See Fig. S11 in the ESI. $\dagger$

Following the characterisation of the [3] rotaxane $3 \mathbf{R} \cdot 12 \mathbf{P F}_{6}$, we were interested in investigating its switching properties, particularly in aqueous solution. The solubility of the [3]rotaxane can be modulated by counterion exchange, given the fact that the $\mathrm{PF}_{6}{ }^{-}$salt is highly soluble in organic solvents such as MeCN and $\mathrm{Me}_{2} \mathrm{CO}$, and the $\mathrm{Cl}^{-}$salt is soluble in aqueous solution. Counterion exchanges were achieved using $\mathrm{NH}_{4} \mathrm{PF}_{6}$ and $n \mathrm{Bu}_{4} \mathrm{NCl}$. The shuttling of the $\mathbf{C B P Q T}^{4+}$ rings between the recognition sites, following reduction to the hexaradical hexacationic RSCC, was monitored electrochemically and also by UV-Vis-NIR spectroscopy since NMR characterisation of the paramagnetic species was not possible.

The reduction potential for $\mathbf{3 R} \cdot \mathbf{1 2} \mathrm{Cl}$ in aqueous solution was determined (Fig. 3) by differential pulse voltammetry using $\mathrm{Ag} / \mathrm{AgCl}$ as a reference. Compared to the free $\mathrm{BIPY}^{2+}$ units in the dumbbell structure $(-615 \mathrm{mV})$ and in the ring $(-410 \mathrm{mV})$, the reduction potential of the [3] rotaxane was significantly shifted $(-368 \mathrm{mV})$. The shift of the $\mathrm{BIPY}^{+}$signal in the [3] rotaxane toward more positive potential indicates the formation of the trisradical complex between the BIPY $^{+\cdot}$ and CBPQT $^{2(+\bullet)}$. Spectroelectrochemistry (SEC) performed (Fig. 4) at an applied potential of $-750 \mathrm{mV}$ showed evidence for the shuttling of the reduced diradical, dicationic $\mathbf{C B P Q T}^{2(+\bullet)}$ rings from the DNP recognition sites to the inner BIPY ${ }^{+}$sites. This

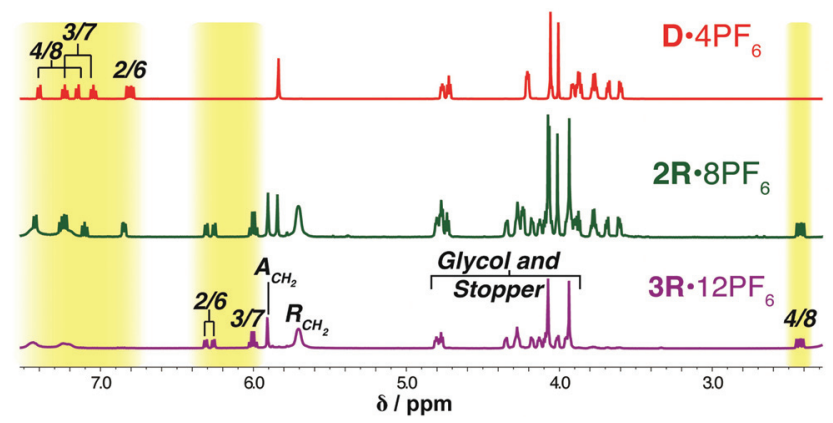

Fig. 2 Partial ${ }^{1} \mathrm{H}$ NMR spectra ( $500 \mathrm{MHz}, \mathrm{CD}_{3} \mathrm{CN}, 298 \mathrm{~K}$ ) comparing the dumbbell $\mathrm{D} \cdot 4 \mathrm{PF}_{6}$, the [2] rotaxane $2 \mathrm{R} \cdot 8 \mathrm{PF}_{6}$, and the [3] rotaxane $3 \mathrm{R} \cdot 12 \mathrm{PF}_{6}$ reveal upfield shifts of the resonances for the DNP protons in the rotaxanes (see Scheme 1 for proton labelling), indicating that the $\mathrm{CBPQT}^{4+}$ rings encircle the DNP units in the oxidised GSCC.

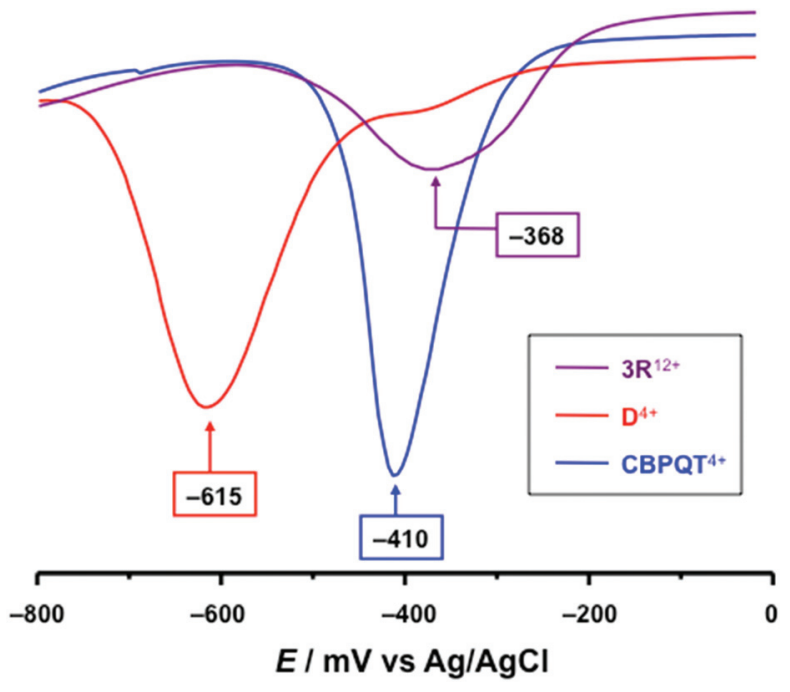

Fig. 3 (a) Differential pulse voltammetry (DPV) of the [3] rotaxane $3 R^{12+}$ (purple curve), dumbbell $\mathrm{D}^{4+}$ (red curve) and $\mathrm{CBPQT}^{4+}$ (blue curve) performed at $0.2 \mathrm{mM}$ sample at $298 \mathrm{~K}$ in $\mathrm{H}_{2} \mathrm{O}-\mathrm{DMF}(9: 1, \mathrm{v} / \mathrm{v})$ with $0.1 \mathrm{M}$ $\mathrm{KNO}_{3}$ as the supporting electrolyte.

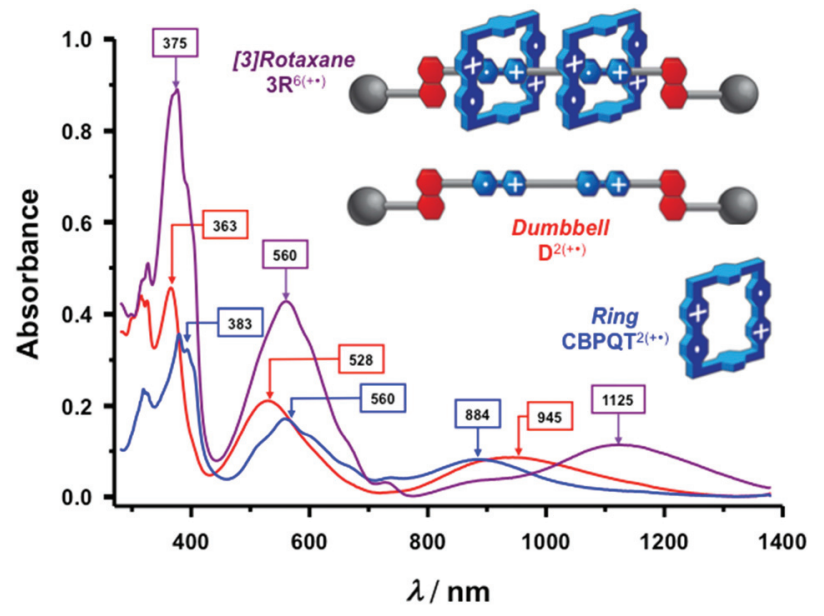

Fig. $4 U V$-Vis Spectra $(60 \mu M, 298 K)$ of $3 R^{6(+\cdot)}$ (purple curve), $D^{2(+\cdot)}$ (red curve) and $\mathrm{CBPQT}^{2(+\cdot)}$ (blue curve) conducted in $\mathrm{H}_{2} \mathrm{O}-\mathrm{DMF}(9: 1$, $\mathrm{v} / \mathrm{v})$ with $0.1 \mathrm{M} \mathrm{KNO}_{3}$ as the supporting electrolyte at an applied potential of $-750 \mathrm{mV}$ vs. $\mathrm{Ag} / \mathrm{AgCl}$ show different absorbances between species in their reduced states.

was revealed by a change in the charge-transfer band corresponding to the interaction between the $\mathbf{C B P Q T}^{4+}$ rings and the DNP units in the GSCC. A comparison of the spectra of the reduced [3] rotaxane species with those of the dumbbell $\mathbf{D}^{2(+\cdot)}$ and ring $\mathbf{C B P Q T}^{2(+\cdot)}$ in their reduced states showed an absorption band centred at $1125 \mathrm{~nm}$ characteristic of the trisradical interaction in the hexaradical, hexacationic [3]rotaxane $3 \mathbf{R}^{6(+\cdot)}$. SEC also showed significantly different absorption profiles for the reduced versus oxidised states of the [3]rotaxane. See Fig. S2 in the ESI. $\uparrow$ In addition to electrochemical stimuli, switching was also achieved by chemical means $-\mathrm{Na}_{2} \mathrm{~S}_{2} \mathrm{O}_{4}$ and 
$\mathrm{Zn}$ dust for reduction in $\mathrm{H}_{2} \mathrm{O}$ and $\mathrm{MeCN}$ respectively, and $\mathrm{O}_{2}$ (air) for oxidation. See Fig. S3 and S4 in the ESI. $\dagger$

In summary, by combining new advances in radical-based MIM motifs with a design that results in relative contractile motion of the rings, we have produced a 'next generation' palindromic [3] rotaxane capable of redox switching in aqueous solution. The radical-pairing recognition motif is incredibly versatile, since it is amenable to switching by electrochemical or chemical stimuli in different media, including aqueous solution. This system brings the dream of artificial muscles that function employing the same mechanism natural muscle uses - namely molecular motion - one step closer. ${ }^{15}$ Operating in aqueous solution enables the integration of this molecular muscle mimic with biological interfaces. Future work will focus on the preparation of derivatives that include conjugation handles for incorporating this molecular switch into micro- and macroscopic materials and biological systems.

\section{Acknowledgements}

The research reported in this publication was supported by the National Institute of General Medical Sciences of the National Institutes of Health (NIH) under Award Number F32GM105403. The content is solely the responsibility of the authors and does not necessarily represent the official views of the NIH. This research is part (Project \#34-949) of the Joint Center of Excellence in Integrated Nano-Systems (JCIN) at King Abdul-Aziz City for Science and Technology (KACST) and Northwestern University (NU). The authors would like to thank both KACST and NU for their continued support of this research. A.C.F. was and E.J.D. is supported by the National Science Foundation (NSF) Graduate Research Fellowship Program. L.S.W. acknowledges support from the International Institute for Nanotechnology (IIN) at NU. J.C.B. was supported by a National Defense Science and Engineering Graduate Fellowship from the Department of Defense and gratefully acknowledges receipt of a Ryan Fellowship from the IIN while at NU.

\section{Notes and references}

1 (a) S. F. M. van Dongen, S. Cantekin, J. A. A. W. Elemans, A. E. Rowan and R. J. M. Nolte, Chem. Soc. Rev., 2014, 43, 99-122; (b) A. Coskun, M. Banaszak, R. D. Astumian, J. F. Stoddart and B. A. Grzybowski, Chem. Soc. Rev., 2012, 41, 19-30; (c) M. von Delius and D. A. Leigh, Chem. Soc. Rev., 2011, 40, 3656-3676; (d) E. R. Kay, D. A. Leigh and F. Zerbetto, Angew. Chem., Int. Ed., 2007, 46, 72-191.

2 (a) P. G. Clark, M. W. Day and R. H. Grubbs, J. Am. Chem. Soc., 2009, 131, 13631-13633; (b) G. Du, E. Moulin, N. Jouault, E. Buhler and N. Giuseppone, Angew. Chem., Int. Ed., 2012, 51, 12504-12508; (c) C. J. Bruns and J. F. Stoddart, Nat. Nanotechnol., 2013, 8, 9-10.
3 (a) B. Alberts, Cell, 1998, 92, 291-294; (b) A.-L. Barabási and Z. N. Oltvai, Nat. Rev. Genet., 2004, 5, 101-113; (c) K. Kinbara and T. Aida, Chem. Rev., 2005, 105, 13771400 .

4 (a) J. Berná, D. A. Leigh, M. Lubomska, S. M. Mendoza, E. M. Pérez, P. Rudolf, G. Teobaldi and F. Zerbetto, Nat. Mater., 2005, 4, 704-710; (b) R. Eelkema, M. M. Pollard, J. Vicario, N. Katsonis, B. S. Ramon, C. W. M. Bastiaansen, D. J. Broer and B. L. Feringa, Nature, 2006, 440, 163-163; (c) B. L. Feringa, J. Org. Chem., 2007, 72, 6635-6652; (d) M. Yamada, M. Kondo, J. Mamiya, Y. Yu, M. Kinoshita, C. J. Barrett and T. Ikeda, Angew. Chem., Int. Ed., 2008, 47, 4986-4988; (e) S. Iamsaard, S. J. Aßhoff, B. Matt, T. Kudernac, J. J. L. M. Cornelissen, S. P. Fletcher and N. Katsonis, Nat. Chem., 2014, 6, 229235.

5 (a) R. Ballardini, V. Balzani, A. Credi, M. T. Gandolfi and M. Venturi, Acc. Chem. Res., 2001, 34, 445-455; (b) D. A. Leigh, J. K. Y. Wong, F. Dehez and F. Zerbetto, Nature, 2003, 424, 174-179; (c) J. F. Stoddart, Chem. Soc. Rev., 2009, 38, 1802; (d) D.-H. Qu and H. Tian, Chem. Sci., 2011, 2, 1011-1015; (e) C. Romuald, A. Ardá, C. Clavel, J. Jiménez-Barbero and F. Coutrot, Chem. Sci., 2012, 3, 1851-1857; (f) B. Lewandowski, G. D. Bo, J. W. Ward, M. Papmeyer, S. Kuschel, M. J. Aldegunde, P. M. E. Gramlich, D. Heckmann, S. M. Goldup, D. M. D'Souza, A. E. Fernandes and D. A. Leigh, Science, 2013, 339, 189-193; ( $g$ ) H. Zhang, Q. Liu, J. Li and D.-H. Qu, Org. Lett., 2013, 15, 338-341; (h) J.-N. Zhang, H. Li, W. Zhou, S.-L. Yu, D.-H. Qu and H. Tian, Chem. Eur. J., 2013, 19, 17192-17200.

6 (a) T. J. Huang, B. Brough, C.-M. Ho, Y. Liu, A. H. Flood, P. A. Bonvallet, H.-R. Tseng, J. F. Stoddart, M. Baller and S. Magonov, Appl. Phys. Lett., 2004, 85, 5391-5393; (b) Y. Liu, A. H. Flood, P. A. Bonvallet, S. A. Vignon, B. H. Northrop, H.-R. Tseng, J. O. Jeppesen, T. J. Huang, B. Brough, M. Baller, S. Magonov, S. D. Solares, W. A. Goddard, C.-M. Ho and J. F. Stoddart, J. Am. Chem. Soc., 2005, 127, 9745-9759; (c) B. K. Juluri, A. S. Kumar, Y. Liu, T. Ye, Y.-W. Yang, A. H. Flood, L. Fang, J. F. Stoddart, P. S. Weiss and T. J. Huang, ACS Nano, 2009, 3, 291-300.

7 Other MIM motifs, such as daisy chains, have been designed to produce a contractile motion. See (a) M. C. Jiménez, C. Dietrich-Buchecker and J.-P. Sauvage, Angew. Chem., Int. Ed., 2000, 39, 3284-3287; (b) M. C. Jimenez-Molero, C. Dietrich-Buchecker and J.-P. Sauvage, Chem. - Eur. J., 2002, 8, 1456-1466; (c) D. Tuncel, O. Ozsar, H. B. Tiftik and B. Salih, Chem. Commun., 2007, 1369-1371; (d) D. Tuncel and M. Katterle, Chem. - Eur. J., 2008, 14, 4110-4116; (e) F. Coutrot, C. Romuald and E. Busseron, Org. Lett., 2008, 10, 37413744; $(f)$ Q. Jiang, H.-Y. Zhang, M. Han, Z.-J. Ding and Y. Liu, Org. Lett., 2010, 12, 1728-1731; (g) Y. Jiang, J.-B. Guo and C.-F. Chen, Org. Lett., 2010, 12, 4248-4251; (h) K. Nakazono and T. Takata, Chem. - Eur. J., 2010, 16, 
13783-13794; ( $i$ ) W. Yang, Y. Li, J. Zhang, N. Chen, S. Chen, H. Liu and Y. Li, Small, 2012, 8, 2602-2607; (j) Z.-J. Zhang, M. Han, H.-Y. Zhang and Y. Liu, Org. Lett., 2013, 15, 16981701; (k) Y. Tokunaga, S. Ikezaki, M. Kimura, K. Hisada and T. Kawasaki, Chem. Commun., 2013, 49, 11749-11751; (l) F. Durola, V. Heitz, F. Reviriego, C. Roche, J.-P. Sauvage, A. Sour and Y. Trolez, Acc. Chem. Res., 2014, 47, 633-645; ( $m$ ) C. J. Bruns, M. Frasconi, J. Iehl, K. J. Hartlieb, S. T. Schneebeli, C. Cheng, S. I. Stupp and J. F. Stoddart, J. Am. Chem. Soc., 2014, 136, 4714-4723; (n) C. J. Bruns, J. Li, M. Frasconi, S. T. Schneebeli, J. Iehl, H.-P. Jacquot de Rouville, S. I. Stupp, G. A. Voth and J. F. Stoddart, Angew. Chem., Int. Ed., 2014, 53, 1953-1958.

8 (a) W. S. Jeon, H.-J. Kim, C. Lee and K. Kim, Chem. Commun., 2002, 1828-1829; (b) H. Li, A. C. Fahrenbach, S. K. Dey, S. Basu, A. Trabolsi, Z. Zhu, Y. Y. Botros and J. F. Stoddart, Angew. Chem., Int. Ed., 2010, 49, 8260-8265; (c) H. Li, A. C. Fahrenbach, A. Coskun, Z. Zhu, G. Barin, Y.-L. Zhao, Y. Y. Botros, J.-P. Sauvage and J. F. Stoddart, Angew. Chem., Int. Ed., 2011, 50, 6782-6788; (d) A. C. Fahrenbach, Z. Zhu, D. Cao, W.-G. Liu, H. Li, S. K. Dey, S. Basu, A. Trabolsi, Y. Y. Botros, W. A. Goddard and J. F. Stoddart, J. Am. Chem. Soc., 2012, 134, 1627516288; (e) J. C. Barnes, A. C. Fahrenbach, D. Cao, S. M. Dyar, M. Frasconi, M. A. Giesener, D. Benítez, E. Tkatchouk, O. Chernyashevskyy, W. H. Shin, H. Li, S. Sampath, C. L. Stern, A. A. Sarjeant, K. J. Hartlieb, Z. Liu, R. Carmieli, Y. Y. Botros, J. W. Choi, A. M. Z. Slawin, J. B. Ketterson, M. R. Wasielewski, W. A. Goddard and J. F. Stoddart, Science, 2013, 339, 429-433.

9 S. Fujii and J.-M. Lehn, Angew. Chem., Int. Ed., 2009, 48, 7635-7638.

10 Y. Liu, S. Saha, S. A. Vignon, A. H. Flood and J. F. Stoddart, Synthesis, 2005, 3437-3445.
11 O. Š. Miljanić, W. R. Dichtel, S. I. Khan, S. Mortezaei, J. R. Heath and J. F. Stoddart, J. Am. Chem. Soc., 2007, 129, 8236-8246.

12 D. B. Amabilino, P. R. Ashton, C. L. Brown, E. Cordova, L. A. Godinez, T. T. Goodnow, A. E. Kaifer, S. P. Newton and M. Pietraszkiewicz, J. Am. Chem. Soc., 1995, 117, 12711293.

13 (a) C. Adelwöhrer, T. Rosenau, E. Kloser, K. Mereiter and T. Netscher, Eur. J. Org. Chem., 2006, 2081-2086; (b) T. Han and C.-F. Chen, J. Org. Chem., 2008, 73, 7735-7742; (c) H. Li, Z. Zhu, A. C. Fahrenbach, B. M. Savoie, C. Ke, J. C. Barnes, J. Lei, Y.-L. Zhao, L. M. Lilley, T. J. Marks, M. A. Ratner and J. F. Stoddart, J. Am. Chem. Soc., 2013, 135, 456-467.

14 (a) R. Huisgen, G. Szeimies and L. Möbius, Chem. Ber., 1967, 100, 2494-2507; (b) H. C. Kolb, M. G. Finn and K. B. Sharpless, Angew. Chem., Int. Ed., 2001, 40, 20042021; (c) C. W. Tornøe, C. Christensen and M. Meldal, J. Org. Chem., 2002, 67, 3057-3064.

15 Many artificial muscle materials are actuated through bulk volume changes or photoisomerisation, as opposed to translational molecular motions. For examples, see (a) Y. Osada, in Polymer Physics, Springer, Berlin, Heidelberg, 1987, pp. 1-46; (b) R. H. Baughman, Synth. Met., 1996, 78, 339-353; (c) A. Lendlein and S. Kelch, Angew. Chem., Int. Ed., 2002, 41, 2034-2057; (d) T. Ikeda, J. Mamiya and Y. Yu, Angew. Chem., Int. Ed., 2007, 46, 506-528; (e) T. Mirfakhrai, J. D. Madden and R. H. Baughman, Mater. Today, 2007, 10, 30-38; (f) M. Irie, Bull. Chem. Soc. Jpn., 2008, 81, 917-926; (g) P. Brochu and Q. Pei, Macromol. Rapid Commun., 2010, 31, 10-36; (h) Y. Takashima, S. Hatanaka, M. Otsubo, M. Nakahata, T. Kakuta, A. Hashidzume, H. Yamaguchi and A. Harada, Nat. Commun., 2012, 3, 1270. 